\title{
The burden of dengue, source reduction measures, and serotype patterns in Myanmar, 2011 to 2015-R2
}

Pwint Mon Oo ${ }^{1 *}$, Khin Thet Wai ${ }^{2}$, Anthony D. Harries ${ }^{3,4}$, Hemant Deepak Shewade ${ }^{5}$, Tin Oo ${ }^{2}$, Aung Thi ${ }^{1}$ and Zaw Lin ${ }^{1}$

\begin{abstract}
Background: Myanmar is currently classified as a high burden dengue country in the Asian Pacific region. The Myanmar vector-borne diseases control (VBDC) program has collected data on dengue and source reduction measures since 1970, and there is a pressing need to collate, analyze, and interpret this information. The aim of this study was to describe the burden of hospital-based dengue disease, dengue control measures, and serotype patterns in Myanmar between 2011 and 2015 .
\end{abstract}

Methods: This was a cross-sectional study using annual records from the Dengue Fever/Dengue Hemorrhagic Fever Prevention and Control Project in Myanmar.

Results: Between 2011 and 2015, there were a total of 89,832 cases and 393 deaths in hospitals, with 97\% of cases being in children. In 2013 and 2015, there was an increased number of cases, respectively at 21,942 and 42,913, while during the other 3 years, numbers ranged from 4738 to 13,806. The distribution of dengue deaths each year mirrored the distribution of cases. Most cases (84\%) occurred in the wet season and 54\% occurred in the delta/lowlands. Case fatality rate (CFR) was highest in 2014 at 7 per 1000 dengue cases, while in the other years, it ranged from 3 to 5 per 1000 cases. High CFR per 1000 were also observed in infants $<1$ year ( $C F R=8)$, adults $\geq 15$ years $(C F R=7)$, those with disease severity grade IV $(C F R=17)$, and those residing in hilly regions $(C F R=9)$. Implementation and coverage of dengue source reduction measures, including larval control, space spraying, and health education, all increased between 2012 and 2015, although there was low coverage of these interventions in households and schools and for water containers. In the 2013 outbreak, dengue virus serotype 1 predominated, while in the 2015 outbreak, serotypes 1, 2, and 4 were those mainly in circulation.

Conclusion: Dengue is a serious public health disease burden in Myanmar. More attention is needed to improve monitoring, recording, and reporting of cases, deaths, and vector control activities, and more investment is needed for programmatic research.

Keywords: Children, Dengue, Dengue hemorrhagic fever, Dengue case fatality, Dengue virus serotypes, Health education, Larval control measures, Myanmar, Space spraying

\footnotetext{
*Correspondence: pwintmonoo@gmail.com

${ }^{1}$ Central Vector Borne Disease Control Programme, Department of Public

Health, Ministry of Health and Sport, Nay Pyi Taw, Myanmar

Full list of author information is available at the end of the article
} 


\section{Background}

Dengue fever is a mosquito-borne tropical disease that usually lasts 2 to 7 days and is caused by the dengue virus $[1,2]$. In a small proportion of cases, the disease develops into (a) life-threatening dengue hemorrhagic fever (DHF) or (b) dengue shock syndrome (DSS). There are no specific drugs for the treatment of dengue, which is merely supportive. The infection is spread by two species of Aedes mosquito, Aedes aegypti (the principal vector) and Aedes albopictus. The virus has four distinct, but closely related, serotypes. Recovery from infection by one serotype provides lifelong immunity against that particular serotype. Cross-immunity to the other serotypes occurs, but this is only partial and temporary, and subsequent infections by other serotypes increase the risk of that person developing severe dengue complications such as DHF or DSS. A novel vaccine (Dengvaxia) has been developed and has been shown to be effective [3-5], but, although it is licensed and in use, it is not yet fully deployed. Thus, prevention is currently focused on reducing the mosquito habitats and limiting human exposure to mosquito bites.

The incidence of dengue has grown dramatically around the world in recent decades, with a 30-fold increase in estimated cases in the last 50 years. On the basis of population data and geostatistical models, the burden of dengue infections globally is estimated at 390 million infections per year, with 96 million of those presenting clinically with mild, moderate, or severe disease [6, 7]. Further modeling suggests that 3.9 billion people living in 128 countries are at risk of infection with dengue viruses [7]. In the World Health Organization (WHO) South-East Asia region and Western Pacific Region, some 1.8 billion people (more than $70 \%$ of the population) are at risk of dengue, and this poses a substantial economic and disease burden on these countries $[1,8]$.

To combat this growing problem in the region, the Asia Pacific Dengue Strategic Plan (2008-2015) was developed with the goal of reversing the rising trend of dengue cases by enhancing preparedness to detect, characterize, and contain outbreaks rapidly and to stop the spread of the virus to new areas [9]. Progress is being made with implementation combined with operational and surveillance response research [10].

Myanmar has seen an escalating number of cases of dengue in the last 10 years, despite vector control efforts, and is currently classified as a high burden dengue country in the Asian Pacific region [8]. There is a prevention and treatment program which works as follows. Patients with dengue are diagnosed in hospitals of all States/Regions of Myanmar, with the diagnosis mainly based on clinical criteria according to 2011 WHO guidelines [11]. Rapid diagnostic test kits for dengue are available, but these are in limited supply and are rarely used. Serotype confirmation can be carried out, but this requires polymerase chain reaction (PCR), which is available at the National Health Laboratory under the Department of Public Health and the Department of Medical Research. PCR is done mainly through research and surveillance in response to outbreaks, but each year, children with dengue are also asked to provide specimens so that information can be obtained about circulating serotypes [12, 13]. Once patients are notified with dengue, source reduction measures (mainly control of mosquito larvae and adult mosquitoes) are implemented along with health education and social mobilization [14].

The Myanmar vector-borne diseases control (VBDC) program has collected data on dengue cases, dengue deaths, and vector control measures since 1970, but there is a pressing need to collate, analyze, and interpret this information and, particularly, to generate location-specific spot maps of the burden of dengue in the country. For a resource-constrained country like Myanmar, this information will enhance cost-effective mitigation strategies and help to promote community engagement for dengue control. The aim of this study, therefore, was to describe the burden of dengue disease, dengue control measures, and serotype patterns in Myanmar over a 5-year period between 2011 and 2015. Specific objectives were to describe for each year: (i) public hospital-reported cases of dengue and deaths, stratified by age, gender, urban/rural residence, disease severity grade, season, and geographical ecology; (ii) dengue vector control measures, including mass larval control, space spraying (fogging), and health education; and (iii) serotype patterns of dengue virus from selected states/regions that were identified in the National Health Laboratory.

\section{Methods \\ Study design}

This was a cross-sectional descriptive study using annual records from the Dengue Fever/Dengue Hemorrhagic Fever (DF/DHF) Prevention and Control Project in Myanmar.

\section{Setting \\ General setting}

Myanmar is located in the Southeast Asia Region, bordering the Republic of China on the north and northeast, Laos on the east, Thailand on the southeast, Bangladesh on the west, and India on the northwest. The country is divided administratively into the Nay Pyi Taw Council Territory and 14 states and regions and consists of 74 districts, 330 townships, 398 towns, 3065 wards, 13,619 village tracts, and 64,134 villages. The main geographical features of the country are the delta region and the central plain surrounded by hills and mountains. Myanmar enjoys a tropical climate with three distinct seasons: hot (February to 
April), wet (May to September), and cool (October to January) [15]. Myanmar has a population of 51 million people with an urban-rural population ratio of 30:70. It has an area of 0.6 million square kilometer and a population density of 76 per $\mathrm{km}^{2}$ [15].

\section{Myanmar DF/DHF prevention and control project}

In Myanmar, the DF/DHF surveillance program was launched in 1964 and dengue fever was made a notifiable disease in 1966. In 1968, the National Committee on DHF was formed and the Aedes Mosquito Control Unit was established. In 1969, sporadic cases of DHF were recorded in Yangon. The first epidemic of DHF in Myanmar was recorded in 1970. At that time, the disease was confined to the Yangon Division only. From 1974 onwards, DHF began to spread to other states and divisions and the disease is now endemic in all states and regions (divisions) except Chin State.

The current National DHF Control Strategy has followed the Asian Pacific Regional Dengue Strategic Plan (2008-2015) [9]. The major goal is to reduce the incidence rates of DF and DHF. The main components of the plan are (i) effective disease and vector surveillance systems based on reliable laboratory and health information; (ii) disease prevention through selective, stratified, and integrated vector control with community education and engagement; (iii) emergency preparedness to prevent and control outbreaks with appropriate contingency plans; (iv) prompt case management of DF/ DHF including early recognition of signs and symptoms to prevent mortality; ( $\mathrm{v}$ ) increased awareness of the community about DF/DHF prevention, control, and management through information, education, and communication; and (vi) improved management and technical support systems and strengthened health facilities for health sector development.

Dengue case surveillance Cases that are admitted to hospital and diagnosed with possible dengue [dengue fever (DF) and DHF/DSS] based on WHO criteria [11] are notified to the health department that then introduces dengue source reduction measures as described below. Case records are kept at the hospital and a focal person from the VBDC team collects these data on a weekly basis through fax, electronic mail, and phone calls. It is estimated that data are collected from $90 \%$ or more of public hospitals in the country. During dengue outbreaks, the reporting is daily rather than weekly. These daily or weekly data are collated by focal persons of the VBDC team with data being transferred upwards from township to district to state/region and finally to the Central VBDC Programme at the Department of Public Health. The Central Programme also reports weekly to the Ministry of Health and Sports. From the Ministry of
Health and Sports, the reports are sent to WHO SEARO through the WHO Country Office of Myanmar.

Dengue vector control measures When a new dengue patient has been identified in an urban ward, the following measures take place within a $100-\mathrm{m}$ radius from the patient's house within 1 week of diagnosis: (i) larval control: insecticide granules (Temephos) are placed into domestic and peri-domestic water containers every 3 months in the wet season to kill mosquito larvae; (ii) mosquito control: space spraying (thermal fogging) using malathion insecticide; and (iii) health education from the VBDC teams by conducting health education sessions, distributing pamphlets, posters, and vinyl printed materials to the general public and transmitting information through mass media channels.

Dengue serotypes During an outbreak of dengue, the National Health Laboratory requests hospitals at selected regions such as Yangon, Mandalay, Sagaing, Nay Pyi Taw, Mon, and Tanintharyi to send specimens from patients with severe complications. Serology was performed assessing for dengue viral-specific antibodies using the $\mathrm{PAMBIO}^{\text {tw }}$ Dengue duo IgM and IgG rapid strip tests. Conventional PCR was then carried out on samples testing seropositive to determine the different serotypes according to the laboratory guidelines. This process is also carried out every year in children from the selected regions.

\section{Study sample and population}

The study includes all patients diagnosed with dengue in public hospitals in Myanmar between 2011 and 2015 . The study also includes information on dengue source reduction measures during the same time period as well as the pattern of dengue serotypes from patients residing in selected states/regions.

\section{Variables, data sources, and data collection}

Data variables for the study included the following: For hospital-reported cases of dengue and deaths-year, month, age group, gender, urban/rural residence, disease severity grade, season, and ecological area of the country [16] for each case. The source of data was the VBDC electronic EXCEL database for aggregate data. For dengue vector control measures: (i) larval control-year, state/region, and coverage in townships, wards, households, and water containers; (ii) space spraying-year, state/region, and coverage in townships, wards, households, and schools; and (iii) health education-year, number of health education sessions, and number of people attending health education sessions. The source of data was the VBDC electronic EXCEL database for aggregate data from selected states/regions. For dengue 
serotypes-year, samples tested, samples seropositive, pattern of serotypes $(1,2,3$, or 4$)$. The source of data was the National Health Laboratory electronic EXCEL database. The operational definitions for the study variables are explained in Table 1.

\section{Analysis and statistics}

Data were extracted and cleaned in the EXCEL File and then exported to EpiData software for analysis (version 2.2.2.183, EpiData Association, Odense, Denmark). A descriptive analysis was performed using frequencies and proportions. Absolute numbers of dengue cases and deaths per year were determined and case rates per 100,000 people and dengue case fatality rates per 1000 cases were calculated. Cases and deaths were also analyzed in relation to age group, gender, urban/rural residence, disease severity grade, season, and ecological area of the country. Nationwide spot maps of dengue cases and deaths across 5 years (2011-2015) by ecological regions were generated through a geographical information system using Quantum GIS software (version 2.18.3, Open source Geospatial Foundation Project).

Table 1 Operational definitions of study variables

\begin{tabular}{|c|c|c|}
\hline SN & Variables & Operational definitions \\
\hline 1 & Ecological regions: & \\
\hline 1.1 & $\begin{array}{l}\text { Delta and lowland (heavy } \\
\text { rainfall more than } 2500 \mathrm{~mm} \text { ) }\end{array}$ & $\begin{array}{l}\text { Ayeyarwady, Yangon, and Bago } \\
\text { regions; Mon and Kayin states }\end{array}$ \\
\hline 1.2 & $\begin{array}{l}\text { Hills (moderate to heavy } \\
\text { rainfall) }\end{array}$ & Kachin, Kayah, Chin, and Shan states \\
\hline 1.3 & $\begin{array}{l}\text { Coastal (heavy rainfall more } \\
\text { than } 2500 \mathrm{~mm} \text { ) }\end{array}$ & Rakhine state and Taninthayi regions \\
\hline 1.4 & $\begin{array}{l}\text { Plains (uneven topography } \\
\text { and rainfall less than } \\
1000 \mathrm{~mm} \text { ) }\end{array}$ & $\begin{array}{l}\text { Magway, Mandalay, Sagaing, } \\
\text { and Nay Pyi Taw regions }\end{array}$ \\
\hline 2 & $\begin{array}{l}\text { Disease severity grade: (WHO } \\
\text { grading of severity of DHF) }\end{array}$ & \\
\hline 2.1 & DF & $\begin{array}{l}\text { Fever with two of the following: } \\
\text { headache, retro-orbital pain, } \\
\text { myalgia, bone pain, rash, and } \\
\text { hemorrhagic manifestations } \\
\text { (No evidence of plasma leakage) }\end{array}$ \\
\hline 2.2 & DHF grade I & $\begin{array}{l}\text { Fever and hemorrhagic } \\
\text { manifestation (positive tourniquet } \\
\text { test) and evidence of plasma leakage }\end{array}$ \\
\hline 2.3 & DHF grade II & $\begin{array}{l}\text { As in grade I plus spontaneous } \\
\text { bleeding }\end{array}$ \\
\hline 2.4 & DHF grade III & $\begin{array}{l}\text { As in grade I or II plus circulatory } \\
\text { failure (weak pulse, narrow pulse } \\
\text { pressure ( } \leq 20 \mathrm{mmHg} \text { ), hypotension, } \\
\text { restlessness) }\end{array}$ \\
\hline 2.5 & DHF grade IV & $\begin{array}{l}\text { As in grade III plus profound shock } \\
\text { with undetectable blood pressure } \\
\text { and pulse }\end{array}$ \\
\hline
\end{tabular}

WHO World Health Organization, DF dengue fever, DHF dengue hemorrhagic fever

\section{Results}

Hospital-reported cases of dengue and dengue deaths

The annual number of hospital-reported cases of dengue and associated deaths are shown in Figs. 1 and 2. During the five-year period, there were a total of 89,832 cases and 393 deaths. In 2013 and 2015, there was an increase in number of cases at 21,942 and 42,913 , respectively, while during the other 3 years the number of cases ranged from 4738 to 13,806 . The distribution of dengue deaths each year mirrored the distribution of cases. The case fatality rate was highest in 2014 at 7 per 1000 dengue cases, while in the other years, this ranged between 3 and 5 per 1000 cases.

The demographic and clinical characteristics of all the hospital-related dengue cases and deaths between 2011 and 2015 are shown in Table 2. Over 95\% of all cases were in children, with those aged 5-9 years being the predominant age group affected. High case fatality rates were observed in infants $<1$ year and adults $\geq 15$ years. No differences were found in cases or deaths between males and females or those residing in urban versus rural settings. The commonest disease severity grade was DF plus DHF grade 1 (42\%), although the majority of deaths and the highest case fatality occurred in those with disease severity grade IV.

The seasonal changes and ecological distribution of hospital-related dengue cases and deaths between 2011 and 2015 are shown in Table 3. The majority of cases and deaths, with the highest case fatality rates, occurred in the wet season from May to September. The majority of cases (85\%) and deaths (82\%) also occurred in persons living in the delta region and the plains, although case fatality was highest in the hills. Figs. 3 and 4 show dengue cases and deaths in relation to the four ecological regions of the country. The five main hot spots for cases were Mon state and the four regions of Yangon, Ayeyarwady, Mandalay, and Sagaing, and the main hot spots for death were Yangon followed by Ayeyarwady region.

\section{Dengue vector control measures and health education}

The implementation of dengue vector control measures in townships, wards, households, and water containers is shown in Table 4. The implementation of larval control measures varied from year to year, although coverage progressively increased at township, ward, and household levels between 2013 and 2015 (Table 4). The proportion of water containers for which there were appropriate larval control measures was low at $<10 \%$ coverage in the last 2 years. The implementation of space spraying as a chemical control measure, especially during outbreaks progressively increased in townships and wards between 2012 and 2015, although coverage at the household and school levels was low, often at $<1 \%$ 


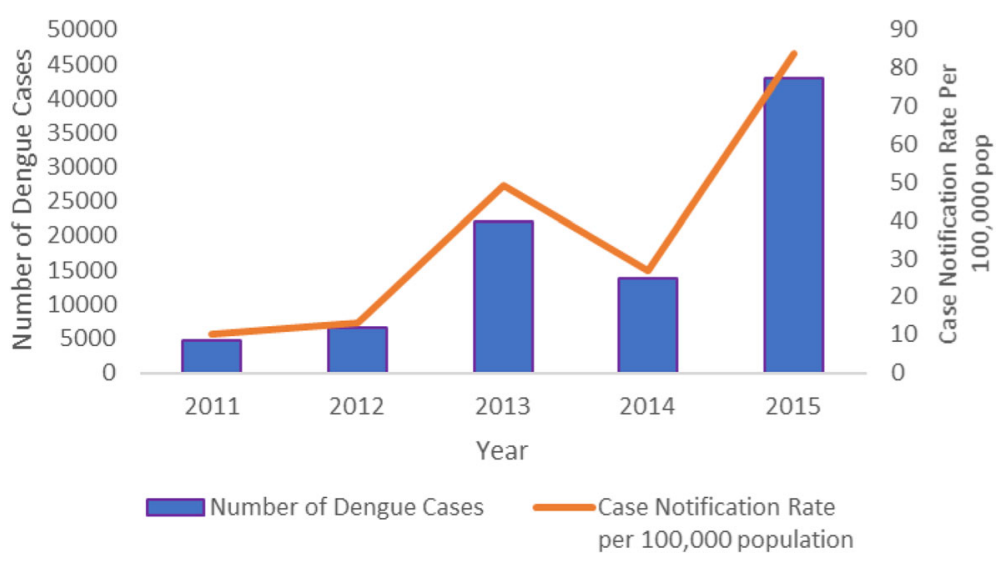

Fig. 1 Annual hospital-reported cases of dengue in Myanmar between 2011 and 2015

(Table 4). Health education sessions for the general public on dengue prevention and control along with numbers attending each year are shown in Table 5, the main findings being a large increase in education sessions and persons attending these sessions, particularly in 2014 and 2015.

\section{Dengue serotype patterns}

Dengue serotype patterns between 2013 and 2015 are shown in Table 6. In the 2013 outbreak, serotype 1 predominated, while in the 2015 outbreak, serotypes 1, 2, and 4 predominated.

\section{Discussion}

This is the first published study from Myanmar assessing the national burden and characteristics of hospital-reported dengue cases and deaths over a 5year period, describing dengue vector control measures and health education in the community and reporting national health laboratory data on serotypes. There were some interesting findings.
The burden of hospital-recorded cases was high and mostly concentrated in children. In two of the five years (2013 and 2015), there were dengue outbreaks, which are variably defined, but in this context equate to case numbers that were significantly increased compared with the previous 5 years [2]. The annual pattern of dengue deaths mirrored that of cases, although, interestingly, case fatality was highest in the 2014, the year between the two outbreaks. The reasons for this are not completely clear, but may relate to the national census being carried out in 2014 providing more accurate population data and a shift to dengue virus serotypes 2 and 4 (which were more common in the 2015 outbreak) and which may be linked to secondary infections and more severe disease [17].

With the 5-year data combined, the highest case fatality was observed in infants and adults (aged 15 years and above). Unfortunately, in the adult population, the national information systems only capture those aged 15 years and above with no further stratification, so we

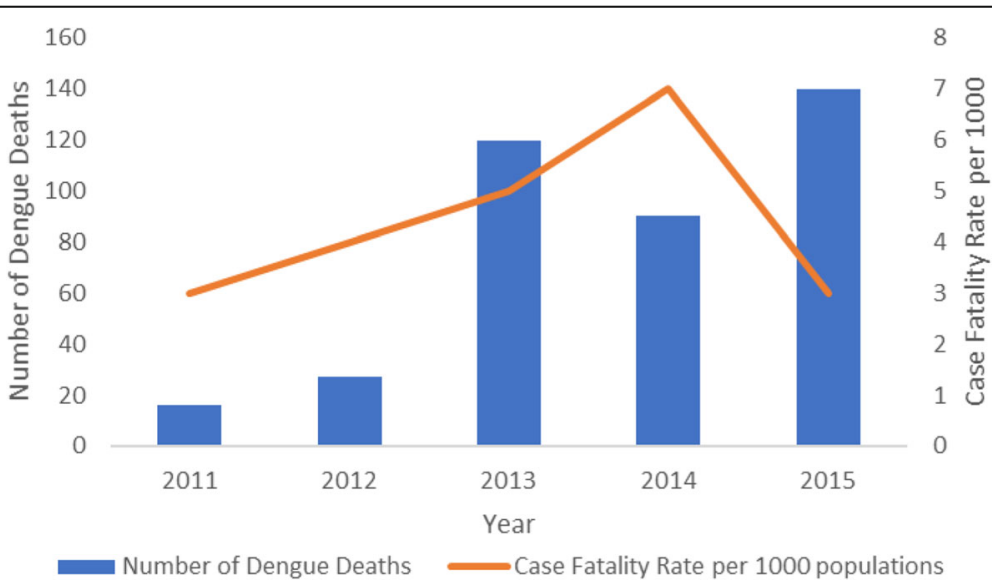

Fig. 2 Annual hospital-reported dengue deaths in Myanmar between 2011 and 2015 
Table 2 Demographic and clinical characteristics in relation to all hospital-reported dengue cases and dengue deaths in Myanmar between 2011 and 2015

\begin{tabular}{|c|c|c|c|c|c|}
\hline \multirow[t]{2}{*}{ Characteristics } & \multicolumn{2}{|c|}{ Dengue cases } & \multicolumn{2}{|c|}{ Dengue deaths } & \multirow{2}{*}{$\begin{array}{l}\text { Case fatality } \\
\text { per } 1000\end{array}$} \\
\hline & $n$ & (\%) & $n$ & (\%) & \\
\hline Total & 89,832 & (100) & 393 & $(100)$ & 4 \\
\hline \multicolumn{6}{|l|}{ Age group in years } \\
\hline$<1$ & 5049 & (6) & 42 & (11) & 8 \\
\hline $1-4$ & 22,613 & (25) & 100 & (25) & 4 \\
\hline $5-9$ & 42,186 & (47) & 187 & (48) & 4 \\
\hline $10-14$ & 17,146 & (19) & 45 & (11) & 3 \\
\hline$\geq 15$ & 2838 & (3) & 19 & (5) & 7 \\
\hline \multicolumn{6}{|l|}{ Gender } \\
\hline Male & 43,875 & (49) & 180 & (46) & 4 \\
\hline Female & 45,957 & (51) & 213 & (54) & 5 \\
\hline \multicolumn{6}{|l|}{ Residence } \\
\hline Urban & 43,282 & (48) & 194 & (49) & 5 \\
\hline Rural & 46,550 & (52) & 199 & (51) & 4 \\
\hline \multicolumn{6}{|l|}{ Disease severity grade } \\
\hline DF and DHF grade I & 37,771 & (42) & 16 & (4) & 0 \\
\hline DHF grade II & 19,244 & (21) & 20 & (5) & 1 \\
\hline DHF grade III & 14,285 & (16) & 44 & (11) & 3 \\
\hline DHF grade IV & 18,532 & (21) & 313 & (80) & 17 \\
\hline
\end{tabular}

$D F$ dengue fever, $D H F$ dengue hemorrhagic fever

do not know which of the older age groups are mainly at risk. A recent systematic review highlighted the importance of old age and non-communicable diseases, such as diabetes mellitus, respiratory disease, and renal failure as risk factors for severe forms of dengue [18], so older adults may particularly be susceptible to DHF and DSS.

Not surprisingly, disease grade 4 accounted for the majority of deaths and was associated with the highest case

Table 3 Seasonal changes and the ecological distribution of hospital-reported dengue cases and dengue deaths in Myanmar between 2011 and 2015

\begin{tabular}{|c|c|c|c|c|c|}
\hline \multirow[t]{2}{*}{ Characteristics } & \multicolumn{2}{|c|}{ Dengue cases } & \multicolumn{2}{|c|}{ Dengue deaths } & \multirow{2}{*}{$\begin{array}{l}\text { Case fatality } \\
\text { per } 1000\end{array}$} \\
\hline & $n$ & $\overline{(\%)}$ & $n$ & $\begin{array}{l}(\%) \\
\end{array}$ & \\
\hline Total & 89,832 & $(100)$ & 393 & $(100)$ & 4 \\
\hline \multicolumn{6}{|l|}{ Season: } \\
\hline Hot (February to April) & 4424 & (5) & 12 & (3) & 3 \\
\hline Wet (May to September) & 75,171 & $(84)$ & 330 & (84) & 4 \\
\hline Cool (October to January) & 10,237 & $(11)$ & 51 & (13) & 1 \\
\hline \multicolumn{6}{|l|}{ Ecological region: } \\
\hline Delta and lowland & 48,412 & (54) & 205 & (52) & 4 \\
\hline Hills & 5732 & (6) & 49 & (12) & 9 \\
\hline Coastal & 8327 & (9) & 24 & (6) & 3 \\
\hline Plains & 27,361 & (31) & 115 & (30) & 4 \\
\hline
\end{tabular}

fatality. The vascular permeability, thrombocytopenia, liver pathology, complement activation, and altered hemostasis in severe dengue have been well characterized through autopsy studies on children dying of dengue in Myanmar [19], but to date, treatment is still supportive effectively with no specific antiviral agents available for targeted therapy.

The finding that dengue cases were more common in the wet season and in the delta and lowland regions concurs with current knowledge about seasonal transmission. High temperatures, relative humidity, heavy rainfall in the wet season, and poor drainage not only assist the main vector, Aedes aegypti, to multiply and adapt to its urban environment, but these factors also favor the propagation of dengue viruses in the mosquito itself [20-23] Case fatality was higher in the hills, and this may relate to health facilities being not as well equipped in these areas, health staff less experienced in the diagnosis and management of dengue, and poor immunity of these populations to the dengue virus [2].

It was encouraging to see the progressive increase in implementation of larval control measures and space spraying in townships and wards, particularly from 2013 to 2015, and this was accompanied by a similar increase in dengue health education sessions and the number of people who attended these sessions. Why there was a decrease in vector control measures between 2011 and 2012 is not clear, but may have been due to poor community participation and engagement at this time. Despite the increases in vector control measures in the most recent years, the implementation coverage of larval control measures in households and for water containers that reflected community participation was still low at less than $25 \%$ and space spraying at households and at schools was even lower at less than $10 \%$. We do not know whether this reflects the true picture or is an indicator of weak monitoring systems, but clearly, the intensive vector control efforts over the last few years did not prevent the dengue outbreak of 2015 .

Finally, the serotype data show that dengue serotype 1 predominated in the 2013 outbreak, with all four serotypes participating in the 2015 outbreak. These findings accord with previous published studies confirming the predominance of serotype 1 and the lack of correlation between serotypes and clinical severity in the 2013 outbreak [24] and the circulation of all four serotypes in the 2015 outbreak [25].

The strengths of this study are the large data set of hospital-recorded cases and deaths from $90 \%$ or more of public hospitals in the country and dengue source control measures from selected states/regions, which make the findings representative of what is happening in the country. The conduct and reporting of this observational study are also in line with internationally recommended 

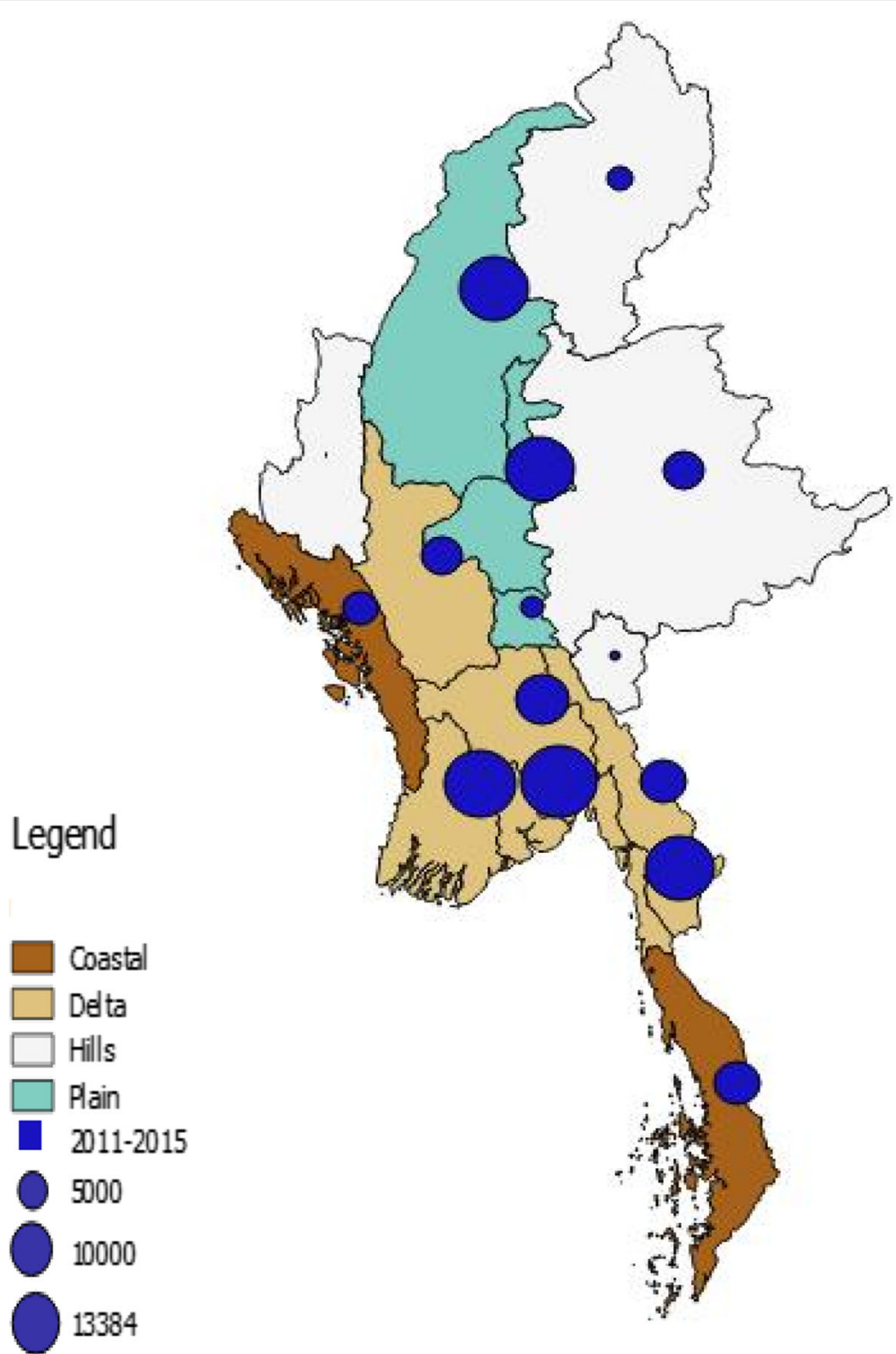

Fig. 3 Distribution of all hospital-reported dengue cases in Myanmar between 2011 and 2015

STROBE guidelines [26]. However, there are a number of limitations. First, the cases and deaths were all health facility based, we do not know from the records whether the dengue cases were based on admission or discharge diagnoses, and there is no information in our study about the community burden of dengue or about the burden of asymptomatic infections. Lack of information on asymptomatic infections is an important epidemiological gap as a recent study has shown that people with asymptomatic infections not only infect mosquitoes, but are more infectious to mosquitoes than those with dengue symptoms [27]. Second, we were unable in dengue cases classified as grade I to differentiate between DF and DHF. Third, we do not know (as stated earlier) whether the low implementation coverage of larval control or space spraying measures in households and schools or in water containers is a true reflection of what is happening or whether this relates to weak monitoring, recording, and reporting. Finally, the data used in the study were all secondary and collected through the routine systems, so we have no means of checking accuracy or validity.

Despite these limitations, there are three important programmatic implications from this study. First, the health facility-based reporting of dengue cases and deaths needs to be revisited to ensure there is functionality at full capacity, the data are collected and transmitted in a timely way, and through regular supervision, the data are quality assured. It is also important for the program to collect a more detailed age-breakdown for those aged 15 years and 


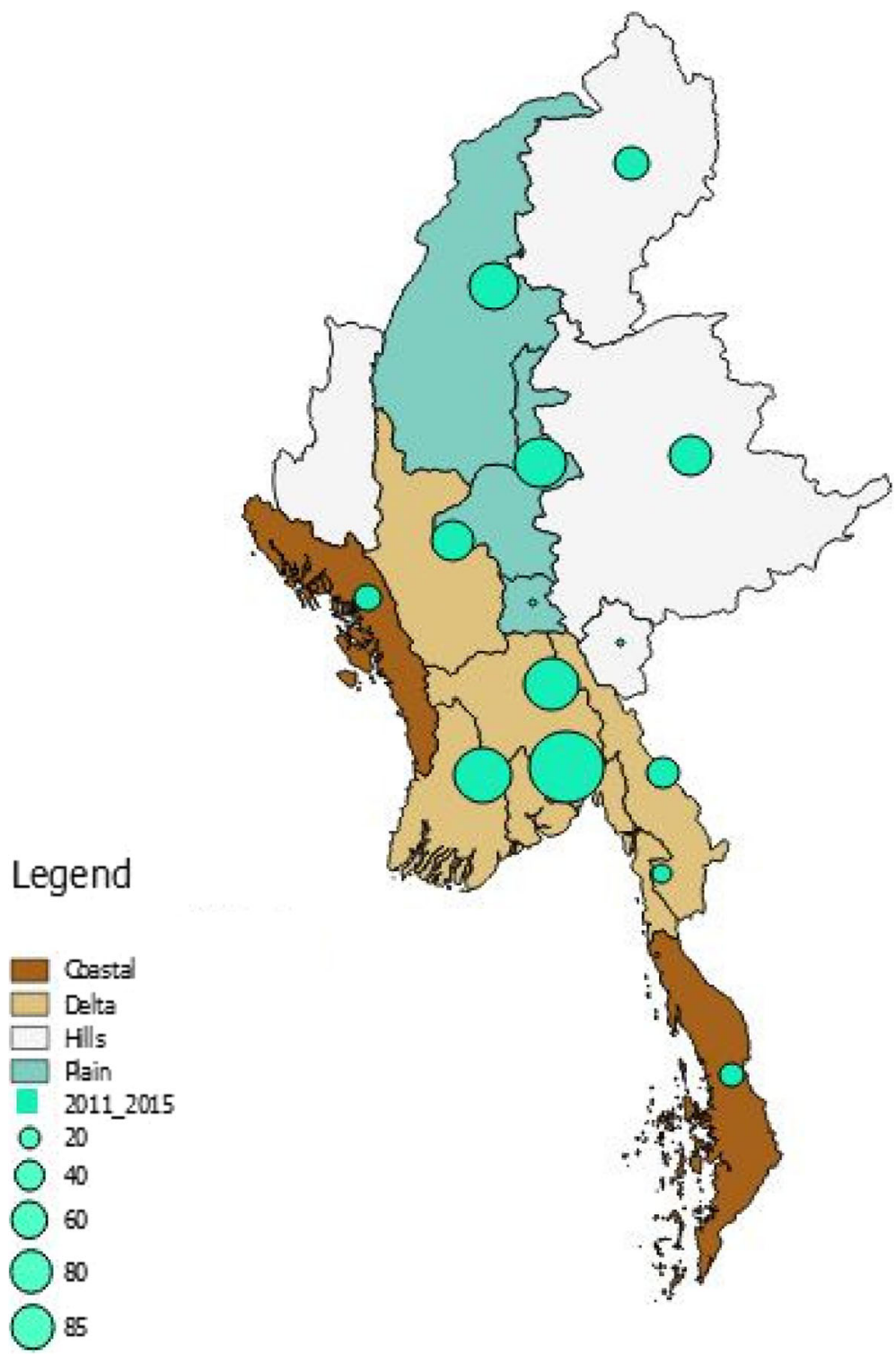

Fig. 4 Distribution of all hospital-reported dengue deaths in Myanmar between 2011 and 2015

above and to divide disease severity grade I into DF and DHF. Whether monitoring can extend to communitylevel disease and asymptomatic infection needs further discussion, but more accurate measurements and estimates of disease burden will be essential for planning vaccination campaigns. Vaccination, in combination with vector control, is seen as a promising tool in the fight against dengue. Currently, there are three candidate live-attenuated vaccines in phase 2/3 (NIH TV003/TV005 and Takeda TDV vaccines) or phase 4 (Sanofi Dengvaxia) trials, although there are many challenges to overcome before efficacy and safety are assured [28].

Second, there is need to strengthen (a) the monitoring and (b) recording of vector control measures, particularly for households, schools, and water containers. Vector control represents a substantial portion of government dengue-related costs, and it is important to note that control of Aedes aegypti is likely to impact not only on dengue but also on chikungunya and Zika viruses. The chikungunya virus has been detected in Myanmar [29, 30], but due to overlap in the clinical presentation with dengue and cross-reactivity of the serological tests, the burden of disease in the country has not been determined. Zika virus was first detected in a foreign national in Myanmar in 2016 [31], but to date, there are no published reports of the burden of Zika virus in the country.

Third, basic science research is crucial to understand more about the virus (serotypes, genotypes, and 
Table 4 Annual implementation of dengue vector control measures in Myanmar between 2011 and 2015

\begin{tabular}{|c|c|c|c|c|c|c|c|c|c|c|c|}
\hline & \multirow{2}{*}{$\begin{array}{l}\text { Total } \\
\text { number }\end{array}$} & \multicolumn{2}{|l|}{2011} & \multicolumn{2}{|l|}{2012} & \multicolumn{2}{|l|}{2013} & \multicolumn{2}{|l|}{2014} & \multicolumn{2}{|l|}{2015} \\
\hline & & $n$ & (\%) & $n$ & (\%) & $n$ & (\%) & $n$ & (\%) & $n$ & (\%) \\
\hline \multicolumn{12}{|l|}{ A: larval control measures } \\
\hline \multicolumn{12}{|c|}{ Implementation of larval control measures at: } \\
\hline Townships & 330 & 277 & (84) & 81 & (25) & 68 & (21) & 157 & (48) & 152 & (46) \\
\hline Wards & 3065 & 2655 & (87) & 931 & (30) & 1364 & (45) & 1716 & (56) & 2026 & (66) \\
\hline Households & $10,889,348$ & $2,753,002$ & $(25)$ & $2,191,259$ & (20) & $1,790,151$ & (16) & $2,729,804$ & $(25)$ & $3,447,524$ & (32) \\
\hline Water containers ${ }^{b}$ & $51,400,000$ & $29,666,676$ & $(58)$ & $5,420,553$ & $(11)$ & $6,755,019$ & (13) & $4,497,076$ & (9) & $10,954,867$ & $(21)$ \\
\hline \multicolumn{12}{|c|}{ B: space spraying measures } \\
\hline \multicolumn{12}{|c|}{ Implementation of space spraying measures at: } \\
\hline Townships & 330 & 120 & (36) & 15 & (5) & 68 & (21) & 84 & (25) & 158 & (48) \\
\hline Wards & 3065 & 855 & (28) & 28 & $(<1)$ & 478 & (16) & 1206 & (39) & 2026 & (66) \\
\hline Households & $10,889,348$ & 31,455 & $(<1)$ & 39,169 & $(<1)$ & 26,293 & $(<1)$ & 43,744 & $(<1)$ & 410,117 & $(<1)$ \\
\hline Schools & 41,000 & 305 & $(<1)$ & 441 & (1) & 139 & $(<1)$ & 1797 & (4) & 2568 & (6) \\
\hline
\end{tabular}

${ }^{\mathrm{a}}$ Total number $=$ total number in the country and is the denominator against which the percentages are calculated

${ }^{b}$ The estimated total number of water containers in Myanmar was based on one container per person living in Myanmar. Previous unpublished surveys have suggested that each resident in the country has one or slightly more than one container with the types of container being drums, cement tanks, ceramic jars, flower vases, car tires, tins, and coconut shells

strains), the immune responses, the immune correlates of protection and risk, and the development of dengue vaccines. National programs, however, would do well to work in partnership with non-governmental organizations, local community-based organizations, and self-help groups to ensure better case management, develop and use point-of-care diagnostics, undertake timely and accurate surveillance/monitoring and reporting, to better engage with the community, to respond to outbreaks, and to implement source reduction measures in households as well as in public spaces [28, 32, 33]. More attention also needs to be given to novel biological, genetic, and behavioral approaches that target mosquitoes such as the use of Wolbachia bacteria strains that infect Aedes aegypti mosquitoes [34] and genetically modified mosquitoes carrying lethal genes [35].

\section{Conclusions}

In conclusion, this study has described the large burden of hospital-recorded dengue in Myanmar between 2011 and 2015, which was concentrated predominately in children and which included two outbreaks in 2013 and

Table 5 Annual number of health education sessions about dengue control measures and numbers attending these sessions in Myanmar between 2011 and 2015

\begin{tabular}{llllll}
\hline & 2011 & 2012 & 2013 & 2014 & 2015 \\
& $n$ & $n$ & $n$ & $n$ & $n$ \\
\hline $\begin{array}{l}\text { Health education } \\
\text { sessions }\end{array}$ & 17,928 & 16,139 & 6005 & 72,045 & 93,664 \\
$\begin{array}{l}\text { Persons attending } \\
\text { health education } \\
\text { sessions }\end{array}$ & $2,608,181$ & $1,793,324$ & $2,254,388$ & $3,137,995$ & $4,841,742$ \\
\hline
\end{tabular}

2015. Case fatality was particularly high in infants aged less than 1 year, adults aged 15 years or more, patients with grade IV disease, and those residing in hilly regions of the country. Implementation and coverage of dengue vector control measures, including larval control, space spraying, and health education, all increased between 2012 and 2015, although there are concerns about low coverage of these interventions in households and schools. Dengue virus serotype 1 predominated in the 2013 outbreak, while all four serotypes circulated in the 2015 outbreak. Dengue is a serious public health disease burden in Myanmar. More attention is needed to improve the monitoring, recording, and reporting of cases, deaths, and vector control activities, and to avoid misclassification bias in reporting hospitalized dengue cases, the notification systems must just report the discharge diagnosis. Finally, more investment needed for programmatic research.

Table 6 Dengue serotypes identified each year in Myanmar between 2011 and 2015

\begin{tabular}{|c|c|c|c|c|c|c|}
\hline \multirow{2}{*}{$\begin{array}{l}\text { Dengue serum samples } \\
\text { and serotypes }\end{array}$} & \multicolumn{2}{|c|}{2013} & \multicolumn{2}{|c|}{2014} & \multicolumn{2}{|c|}{2015} \\
\hline & $\bar{n}$ & $(\%)^{a}$ & $n$ & $(\%)^{a}$ & $n$ & $(\%)^{a}$ \\
\hline Total serum samples tested: & 230 & & 21 & & 37 & \\
\hline Samples seronegative & 148 & & 20 & & 1 & \\
\hline Samples seropositive: & 82 & & 1 & & 36 & \\
\hline Serotype 1 & 44 & (54) & - & & 9 & $(25)$ \\
\hline Serotype 2 & 4 & (5) & - & & 11 & (31) \\
\hline Serotype 3 & 11 & (13) & 1 & (100) & 4 & (11) \\
\hline Serotype 4 & 23 & (28) & - & & 12 & (33) \\
\hline
\end{tabular}

${ }^{a}$ Numbers in percentages are column percentages and refer to serum samples seropositive 


\section{Abbreviations}

DF/DHF: Dengue Fever/Dengue Hemorrhagic Fever; DSS: Dengue shock syndrome; VBDC: Vector-borne disease control; WHO: World Health Organization

\section{Acknowledgements}

This research was conducted through the Structured Operational Research and Training Initiative (SORT IT), a global partnership led by the Special Programme for Research and Training in Tropical Diseases at the World Health Organization (WHO/TDR). The model is based on a course developed jointly by the International Union Against Tuberculosis and Lung Disease (The Union) and Medécins sans Frontières (MSF/Doctors Without Borders). The specific SORT IT program which resulted in this publication was jointly organized and implemented by The Centre for Operational Research, The Union, Paris, France; The Department of Medical Research, Ministry of Health and Sports, Myanmar; The Department of Public Health, Ministry of Health and Sports, Myanmar; The Union Country Office, Mandalay, Myanmar; The Union South-East Asia Office, New Delhi, India; the Operational Research Unit (LUXOR), MSF Brussels Operational Center, Luxembourg; and Burnet Institute, Australia.

\section{Funding}

The training program, within which this paper was developed, and the open access publication costs were funded by the Department for International Development (DFID), UK, and La Fondation Veuve Emile Metz-Tesch (Luxembourg). The funders had no role in study design, data collection and analysis, decision to publish, or preparation of the manuscript.

\section{Availability of data and materials}

All data generated or analyzed during this study are included in this published article.

\section{Authors' contributions}

PMO designed the study, collected and analyzed data, and wrote the first draft. KTW, ADH, and HDS participated in the design of the study, data analysis, and manuscript writing. All authors participated in data interpretation and preparation of the manuscript, and all authors read and approved the final manuscript.

\section{Ethics approval and consent to participate}

Permission to use the secondary data for this study was obtained from the VBDC. Ethics approval in Myanmar was obtained from the Ethics Review Committee on Medical Research involving Human Subjects, Department of Medical Research, Ministry of Health and Sports. Ethics approval was also obtained from the Union Ethics Advisory Group, International Union against Tuberculosis and Lung Disease, Paris, France. Informed patient consent to participate was not required because aggregate and secondary programmatic data were used.

\section{Consent for publication}

Consent to publish was obtained from the Ministry of Health and Sports.

\section{Competing interests}

The authors declare that they have no competing interests.

\section{Publisher's Note}

Springer Nature remains neutral with regard to jurisdictional claims in published maps and institutional affiliations.

\section{Author details}

${ }^{1}$ Central Vector Borne Disease Control Programme, Department of Public Health, Ministry of Health and Sport, Nay Pyi Taw, Myanmar. ${ }^{2}$ Department of Medical Research, Yangon, Myanmar. ${ }^{3}$ International Union against Tuberculosis and Lung Disease, Paris, France. ${ }^{4}$ London School of Hygiene and Tropical Medicine, London, UK. ${ }^{5}$ International Union against Tuberculosis and Lung Disease (The Union), South-East Asia Office, New Delhi, India.
Received: 6 June 2017 Accepted: 18 October 2017

Published online: 02 November 2017

\section{References}

1. World Health Organization. Dengue and severe dengue. Fact Sheet. Updated July 2016. WHO, Geneva, Switzerland. Available: http://www.who. int/mediacentre/factsheets/fs117/en/. Accessed 29 May 2017.

2. Castro MC, Wilson ME, Bloom DE. Dengue 1. Disease and economic burdens of dengue. Lancet Infect Dis. 2017;17:e70-8. Available: http://dx.doi. org/10.1016/S1473-3099(16)30545-X. Accessed 29 May 2017

3. Khetarpal N, Khanna I. Dengue fever: causes, complications and vaccine strategies. J Immunonol Res. 2016;2016:6803098. doi:10.1155/ 2016/6803098. Available: https://www.hindawi.com/journals/jir/ Accessed 29 May 2017

4. Nealon J, Taurel AF, Capeding MR, et al. Symptomatic dengue disease in five South-East Asian countries; epidemiological evidence from a dengue vaccine trial. PLoS Negl Trop Dis. 2016;10:e0004918.

5. Pang T, Mak TK, Gubler DJ. Dengue 2. Prevention and control of dengue-the light at the end of the tunnel. Lancet Infect Dis. 2017;17: e79-87. Available: http://dx.doi.org/ 10.1016/ S1473-3099(16)30471-6. Accessed 29 May 2017

6. Bhatt S, Gething PW, Brady OJ, et al. The global distribution and burden of dengue. Nature. 2013;496:504-7.

7. Brady OJ, Gething PW, Bhatt $\mathrm{S}$, et al. Refining the global spatial limits of dengue virus transmission by evidence-based consensus. PLoS Negl Trop Dis. 2012;6:e1760

8. Shepard DS, Undurraga EA, Halasa YA. Economic and disease burden of dengue in South East Asia. PLoS Negl Trop Dis. 2013;7:e2055.

9. World Health Organization. The dengue strategic plan for the Asia Pacific Region 2008-2015. WHO Western Pacific Region, Manila, Philippines. Available: www.wpro.who.int/mvp/Dengue_Strategic_Plan. pdf. Accessed 29 May 2017.

10. Tambo E, Chen JH, Zhou XN, Khater EIM. Outwitting dengue threat and epidemics resurgence in Asia-Pacific countries: strengthening integrated dengue surveillance, monitoring and response systems. Infect Dis Poverty. 2016;5:56.

11. World Health Organization. Comprehensive guidelines for prevention and control of dengue and dengue hemorrhagic fever, revised and expanded edition. New Delhi. WHO, South East Asia Regional Office 2011. Available: www.searo.who.int/entity/vector_borne_tropical_diseases/documents/.../en/. Accessed 29 May 2017.

12. Thu HM, Lowry K, Myint TT, et al. Myanmar dengue outbreak associated with displacement of serotypes 2, 3 and 4 by dengue 1. Emerg Infect Dis. 2004;10:593-7.

13. Myat TW, Thu HM, Kyaw YM, et al. Identification of dengue virus serotypes in children with dengue infection admitted to Yangon Children's Hospital in 2014. Myanmar Health Sci Res J. 2016;28:1-5. Available: www.myanmarhsrj. com/. Accessed 29 May 2017

14. Department of Health, Ministry of Health, Myanmar. Annual Report of Vector Borne Diseases Control Programme, Nay Pyi Taw, 2013. Available: www.moh.gov.mm/. Accessed 29 May 2017

15. Ministry of Health. Health in Myanmar 2014. The Republic of the Union of Myanmar. Available: www.moh.gov.mm/. Accessed 29 May 2017.

16. Tun A, Myat SM, Gabrielli AF, Montresor A. Control of soil-transmitted helminthiasis in Myanmar: results of 7 years of deworming. Tropical Med Int Health. 2013;18:1017-20.

17. Gupta BP, Singh S, Kurmi R, Molla R, Sreekumar E, Manandhar KD. Reemergence of dengue virus serotype 2 strains in the 2013 outbreak in Nepal. Indian J Med Res. 2015;142(supplement):1-6. doi:10.4103/ 0971-5916.176564.

18. Toledo J, George L, Martinez E, et al. Relevance of non-communicable comorbidities for the development of the severe forms of dengue: a systematic literature review. PLoS Negl Trop Dis. 2016;10:e0004284.

19. Aye KS, Charngkaew K, Win N, et al. Pathologic highlights of dengue hemorrhagic fever in 13 autopsy cases from Myanmar. Hum Pathol. 2014:45:1221-33.

20. Thu HM, Aye KM, Thein S. The effect of temperature and humidity on dengue virus propagation in Aedes aegypti mosquitos. Southeast Asian J Trop Med Public Health. 1998;29:280-4. 
21. Wai KT, Arunachalam N, Tana S, et al. Estimating dengue vector abundance in the wet and dry season: implications for targeted vector control in urban and peri-urban Asia. Pathog Glob Health. 2012;106:436-45.

22. Liu-Helmersson J, Stenlund H, Wilder-Smith A, Rocklov J. Vectorial capacity of Aedes aegypti: effects of temperature and implications for global dengue epidemic potential. PLoS One. 2014;9:e89783.

23. Heinen LBS, Zuchi N, Cardoso BF, et al. Dengue outbreak in Mato Grosso State, Midwestern Brazil. Rev Inst Med Trop Sao Paulo. 2015;57:489-96.

24. Ngwe Tun MM, Kyaw AK, Makki N, et al. Characterization of the 2013 dengue epidemic in Myanmar with dengue virus 1 as the dominant serotype. Infect Genet Evol. 2016;43:31-7.

25. Kyaw AK, Ngwe Tun MM, Moi ML, et al. Clinical, virological and epidemiological characterization of dengue outbreak in Myanmar, 2015. Epidemiol Infect. 2017:1-12. doi:10.1017/S0950268817000735.

26. Von Elm E, Altman DG, Egger M, et al. The Strengthening the Reporting of Observational Studies in Epidemiology (STROBE) Statement: guidelines for reporting observational studies. Lancet. 2007:370:1453-7.

27. Duong V, Lambrechts L, Paul RE, et al. Asymptomatic humans transmit dengue virus to mosquitoes. Proc Natl Acad Sci U S A. 2015;112:14688-93.

28. Katzelnick LC, Coloma J, Harris E. Dengue 3. Dengue: knowledge gaps, unmet needs, and research priorities. Lancet Infect Dis. 2017;17:e88-e100.

29. Tun MM, Thant KZ, Inoue $S$, et al. Detection of east/central/south African genotype of chikungunya virus in Myanmar, 2010. Emerg Infect Dis. 2014;20:1378-81.

30. Furuya-Kanamori L, Liang S, Milinovich G, et al. Co-distribution and coinfection of chikungunya and dengue viruses. BMC Infect Dis. 2016;16:84.

31. World Health Organization. First case of Zika virus infection detected in Myanmar; mosquito control measures must be at the forefront of the fight against vector-borne diseases. October 2016. Available: www.searo.who.int/ myanmar/areas/zika_firstcaseinmyanmar/en/. Accessed 30 May 2017].

32. Arunachalam N, Tana S, Espino F, et al. Eco-bio-social determinants of dengue vector breeding: a multi-country study in urban and periurban Asia. Bull World Health Organ. 2010;88:173-84.

33. Wai KT, Htun PT, Tin O, et al. Community-centred eco-bio-social approach to control dengue vectors: an intervention study from Myanmar. Pathog Glob Health. 2012;106:461-8.

34. Hoffmann AA, Montgomery BL, Popovici J, et al. Successful establishment of wolbachia in Aedes populations to suppress dengue transmission. Nature. 2011:476:454-7.

35. Carvalho DO, McKemey AR, Garziera L, et al. Suppression of a field population of Aedes aegypti in Brazil by sustained release of transgenic male mosquitoes. PLoS Negl Trop Dis. 2015;9:e0003864.

\section{Submit your next manuscript to BioMed Central and we will help you at every step:}

- We accept pre-submission inquiries

- Our selector tool helps you to find the most relevant journal

- We provide round the clock customer support

- Convenient online submission

- Thorough peer review

- Inclusion in PubMed and all major indexing services

- Maximum visibility for your research

Submit your manuscript at www.biomedcentral.com/submit

) Biomed Central 